\title{
Evaluation of the Results of Antiglide Plating of Vertical Medial Malleolus Fractures Ali El-Alfy ${ }^{1}$, Ashraf Abd-ELdayem ${ }^{1}$, Ahmed Mashhour Gaber ${ }^{1}$, Ahmed Mohamed Abdelrahman Ben Alashher*2 ${ }^{1}$ Department of Orthopedic Surgery, Faculty of Medicine - Zagazig University, Egypt ${ }^{2}$ Department of Orthopedic Surgery, Faculty of Medicine - Tripoli University, Libya. \\ *Corresponding Author: Ahmed Mohamed Abdelrahman Ben Alashher, Mobile: (+20) 01069067723, Email: ahmed.alshher@gmail.com
}

\begin{abstract}
Background: Vertical fractures of the medial malleolus are fixed with cancellous screws placed perpendicular to the fracture site. It is important to buttress the fracture by placing a screw with a washer at the proximal apex of the fracture or to use a small tubular plate or T-plate as a buttress. Objective: To assess the radiological and functional outcomes of open reduction and internal fixation with $\mathrm{T}$-shaped plate (antiglide plate) of vertical shear medial malleolus fracture.

Patients and Methods: This was clinical trial study included 22 adult patients with vertical shear medial malleolus fracture who were admitted to Orthopedic Surgery Department, Zagazig University Hospitals in the period from January 2019 to February 2020. They were treated by internal fixation with T-shaped plate (antiglide plate). In this study, we used the Biard and Jackson ankle scoring for assessment of result.

Results: The union duration was $12.1 \pm 2.2$ weeks ranged from 9 to 16 weeks, most of the studied group (59.1\%) had healing time ranged from 9 to 12 weeks. No complications and only two patients $(9.1 \%)$ had superficial infection with no other complications. Biard and Jackson score was $95.3 \pm 4.9$ ranged from 76 to 98 . Most of the studied group (68.2\%) had excellent outcome, $22.7 \%$ of them had good outcome and $9.0 \%$ had poor outcome.

Conclusions: Surgical management of vertical shear of medial malleolus fracture give excellent anatomical reduction and rigid fixation to restore articular congruity, help to facilitate early mobilization and hence to achieve optimal ankle function.
\end{abstract}

Keywords: Medial malleolus, Fracture fixation, Fractures.

\section{INTRODUCTION}

Vertical shear fractures of the medial malleolus occur through supination-adduction loading of the talus onto the articular surface of the medial malleolus ${ }^{(1,2)}$. Vertical shear fractures of the medial malleolus are less common than transverse fractures. There are wide varieties of techniques available for fixation of these fractures, including various cortical screws, cancellous screws, tension bands, and antiglide plates ${ }^{(3)}$. Fixation of these fractures must be sufficient to maintain stable reduction of the ankle joint articular surface allowing early range of motion, maintaining congruency of the ankle joint, and decreasing the risk of future post-traumatic arthritis to maximize functional outcome ${ }^{(4)}$.

These fractures are often treated successfully with buttress or antiglide plates and screws with neutralization plates ${ }^{(5)}$. This study aimed to assess the radiological and functional outcomes of open reduction and internal fixation with T-SHAPED PLATE (ANTIGLIDE PLATE) OF VERTICAL SHEAR MEDIAL MALLEOLUS FRACTURE.

\section{PATIENTS AND METHODS}

Clinical data of 22 adult patients with vertical shear medial malleolus fracture who were admitted to Orthopedic Department included 12 males (54.5\%) and 10 females (45.5\%). The mean age of the patients in the current study was $44.9 \pm 14.7$ years ranging from 21 to 65 years. About half of the studied group $(45.4 \%)$ had age ranged from 50 to 65 years. The fourteen (14) patients have isolated vertical medial malloulus fracture, which were fixated by small $\mathrm{T}$ antiglide plate, the other Eight (8) patients had vertical medial malleolus fracture associated with lateral malleolus which were fixated one third semi tubular plate then fixation of the vertical medial malleolus fracture by small $\mathrm{T}$ antiglide plate.

Ethical and patients' approval: The study was approved by the Institutional Ethics Committee of Zagazig University and informed written consents were taken from patients and/or their caregivers. This Work was performed according to the code of Ethics of the World Medical Association (Declaration of Helsinki) for studies involving humans.

Inclusion criteria: Age above 18 years. Closed / Open Gustilo Type I, II.

Exclusion criteria: Open fracture type III. Patients medically unfit for surgery. Timing of surgery: During $1^{\text {st }}$ week after injury.

All patients were examined both clinically and radiological on admission to the hospital, 12 patients were done operation at same day of admission, and 10 patients' operations were done after 5 day of admission due to swelling and ecchymosis. Air way, breathing, circulation, vital signs and conscious level was assessed. 
All patients were presented with pain on the injured ankle and tenderness, limited movement around injured ankle, non weight bearing on injured ankle and edema on the injured ankle. 3 plain $\mathrm{X}$-rays views were obtained for each case (antero-posterior - lateral anteroposterior with the limb internally rotated 20 degrees "mortise view" on the ankle joint.

\section{Operative Procedure:}

The anterior part of the fracture site was exposed, the periosteum was freed from the edges of the medial malleolus to the distal tibial joint surface and the joint was inspected. the periosteum was removed posteriorly only sufficiently to control reduction (Figure 1).

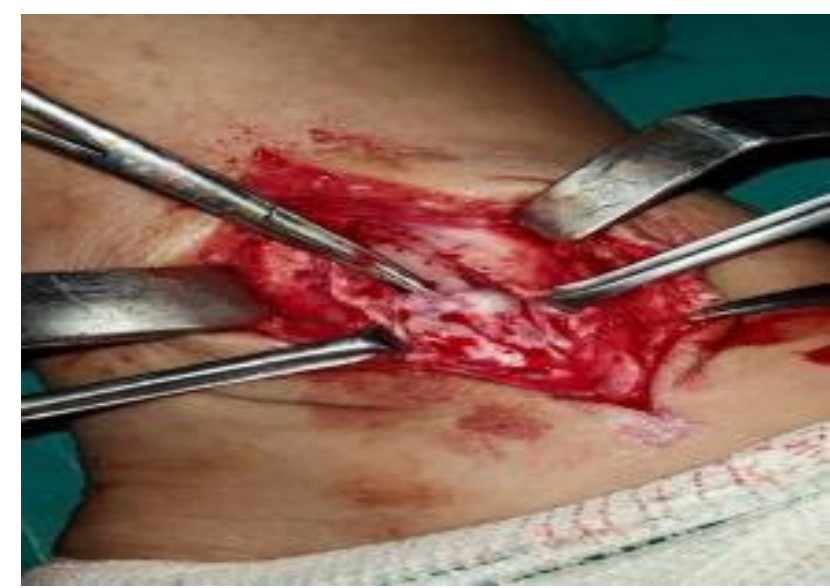

Figure (1): Medial malleolus surgical dissection and exposure of the fracture site.

Any small, loose fragments which may prevent anatomic reduction was removed and the periosteum was freed from the bone edges. In the presence of an impacted medial corner fragment, the main vertical fracture plane was gently opened by retraction of the medial malleolus medially (opening the book).

\section{Application of plate:}

Once the fracture is identified and cleared of interposed periosteum in usual fashion, the anatomic reduction is confirmed on anteroposterior and lateral fluoroscopic images, the small $\mathrm{T}$ plate is contoured to the center of medial aspect of the medial malleolus. Positioning of the plate firmly by hand so that proximal two holes lie on the main body of the tibia and the distal hole of $\mathrm{T}$ plate lie on the medial malleolar fragment. The screw hole just proximal to the fracture site is filled first by $3.5 \mathrm{~mm}$ cortical screws to prevents further proximal displacement of the fracture, then the distal hole was filled to the fracture site by $4.0 \mathrm{~mm}$ cancellous screws After filling the all holes of plate by cortical and cancellous screws, confirm the position of plate and reduction by antero-posterior and lateral fluoroscopic images. It was essential to certain that no screws violates the ankle joint (Figure 2).

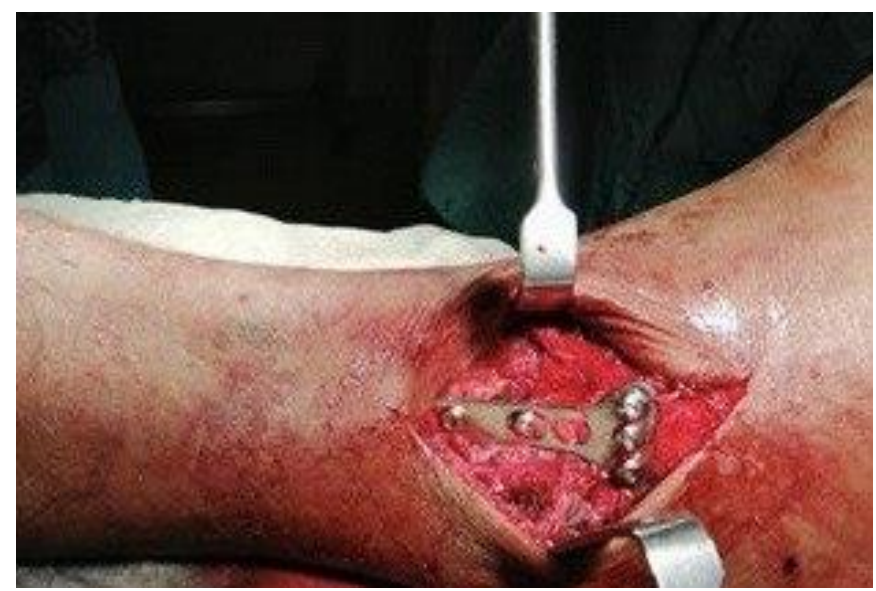

Figure (2): Medial malleolus fixation by small T antiglide plate.

After irrigation of the surgical site by normal saline, the periosteum layer and subcutaneous and skin layer were closed with suture. In case with lateral malleolus, we start by closing lateral site incision then closing medial site incision. Dressing and sterile 4 x 4 gauze dressing are placed over the wound. Standard short leg plaster splint is applied for immediate postoperative comfort.

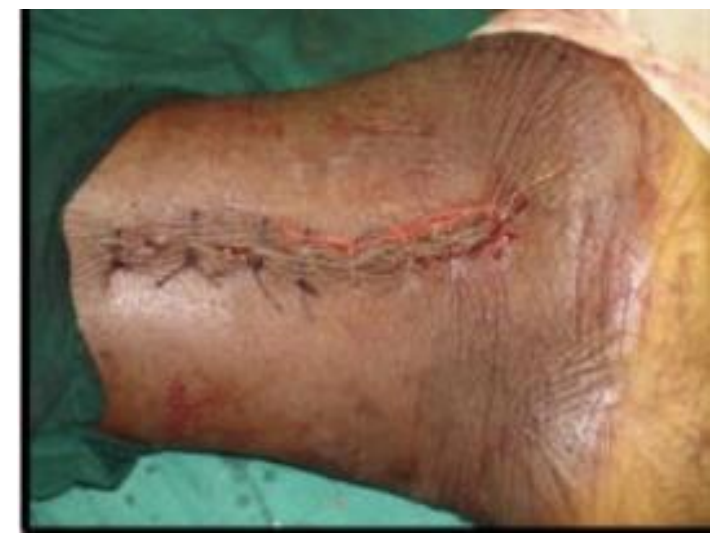

Figure (3): Skin incision after closure.

\section{Post-operative management:}

Post operatively, all patients received Antibiotics consisting of cefotaxime and amikacin were continued for 5 days. Analgesics and anti-edematous drugs were given. Elevation of the affected limb was done. X-rays anteroposterior, lateral and mortise views were taken. Wounds were inspected on 3rd day and sutures were removed on $14^{\text {th }}$ post-operative day on an average. Below knee plaster of Paris cast was applied. Discharged patients with instruction of non-weight bearing crutch walk for a period of 6 weeks and to come for follow-up after 2 week. 


\section{Follow-up:}

Patients were followed up at 2 weeks, 4 weeks and 6 weeks post operatively. After two weeks remove the stitch and change the slab. At 6 weeks $x$ - ray of the ankle was taken both AP and lateral views and looked for signs of fracture union and then were advised for partial weight bearing for further period of 6 weeks with elevation of the limb at night times. Regular follow up was done at 1,2 and 6 months after discharge till the fracture united. Patients were allowed full weight bearing on the affected limb after three mouths.

\section{Statistical analysis:}

Data were verified, coded by the researcher and analyzed using IBM-SPSS Statistics for windows, version 23.0 (Copyright IBM Corp., Armonk, N.Y., USA, 2015). Descriptive statistics: Means, standard deviations, medians, ranges and percentages were calculated. Test of significances: chi-square test was used to compare the difference in distribution of frequencies among different groups. For continuous variables; independent t-test analysis was carried out to compare the means of dichotomous data. There was no specific calculation of the sample size. A significant $\mathrm{p}$ value was considered when it is equal or less than 0.05 .

\section{RESULTS}

This study showed that $63.6 \%$ of the studied group did not have any associated injury and $36.4 \%$ had fracture of lateral malleolus as an associated injury (Table 1).

Table (1): Associated injury among the studied group

\begin{tabular}{|c|c|c|}
\hline Associated injury & NO(22) & \% \\
\hline \hline Absent & 14 & $63.6 \%$ \\
\hline $\begin{array}{c}\text { Present } \\
\text { Fracture of lateral } \\
\text { malleolus }\end{array}$ & 8 & $36.4 \%$ \\
\hline
\end{tabular}

This study showed that the mean time of union duration of the studied group was $12.1 \pm 2.2$ weeks ranged from 9 to 16 weeks. Most of the studied group (59.1\%) had healing time ranged from 9 to 12 weeks (Table 2).

Table (2): Time of union among the studied group

\begin{tabular}{|c|c|c|}
\hline \multirow{2}{*}{ Variable } & \multicolumn{2}{|c|}{$\begin{array}{c}\text { The studied group } \\
(\mathbf{2 2})\end{array}$} \\
\cline { 2 - 3 } & NO (22) & $\mathbf{\%}$ \\
\hline Time of union & & \\
9-12 weeks & 13 & $59.1 \%$ \\
13-16 weeks & 9 & $40.9 \%$ \\
\hline
\end{tabular}

This study showed that at the end of the follow up, 15 patients $(68.2 \%)$ had no pain and 7 patients $(31.8 \%)$ had mild pain with strenuous activity. At the end of the follow up, 20 patients $(90.9 \%)$ were able to walk desired distances without limp or pain while 2 patients $(9.1 \%)$ were able to walk desired distances with mild limp or pain. In addition, at the end of the follow up, 18 patients $(81.8 \%$ ) were able to run desired distances without pain, 3 patients $(13.6 \%)$ were able to run desired distances with slight pain while only one patient $(4.5 \%)$ had moderate restriction in ability to run with mild pain. Moreover, by the end of the follow up, 20 patients $(90.9 \%)$ had clinical stability of the ankle and only two patients $(9.1 \%)$ had instability with sports activities. Finally, at the end of the follow up, the motion of the ankle of 16 patients $(72.7 \%)$ were within $10^{\circ}$ of uninjured ankle, four patients (18.2\%) had motion of ankle within $15^{\circ}$ of uninjured ankle and two patients $(9.1 \%)$ had motion of ankle within $20^{\circ}$ of uninjured ankle (Table 3).

Table (3): Among the studied group

\begin{tabular}{|c|c|c|}
\hline Variable & \multicolumn{2}{|c|}{ The studied group (22) } \\
\hline & NO (22) & $\%$ \\
\hline \multicolumn{3}{|l|}{ Pain intensity } \\
\hline $\begin{array}{l}\text { Mild pain with strenuous } \\
\text { activity }\end{array}$ & 15 & $68.2 \%$ \\
\hline No pain & 7 & $31.8 \%$ \\
\hline \multicolumn{3}{|l|}{ Ability to walk } \\
\hline $\begin{array}{l}\text { Able to walk desired } \\
\text { distances without limp } \\
\text { or pain }\end{array}$ & 20 & $90.9 \%$ \\
\hline $\begin{array}{l}\text { Able to walk desired } \\
\text { distances with mild limp } \\
\text { or pain }\end{array}$ & 2 & $9.1 \%$ \\
\hline \multicolumn{3}{|l|}{ Ability to run } \\
\hline $\begin{array}{l}\text { Able to run desired } \\
\text { distances without pain }\end{array}$ & 18 & $81.8 \%$ \\
\hline $\begin{array}{l}\text { Able to run desired } \\
\text { distances with slight } \\
\text { pain }\end{array}$ & 3 & $13.6 \%$ \\
\hline $\begin{array}{l}\text { Moderate restriction in } \\
\text { ability to run, with mild } \\
\text { pain }\end{array}$ & 1 & $4.5 \%$ \\
\hline \multicolumn{3}{|l|}{ Stability of ankle } \\
\hline No clinical instability & 20 & $90.9 \%$ \\
\hline $\begin{array}{l}\text { Instability with sports } \\
\text { activities }\end{array}$ & 2 & $9.1 \%$ \\
\hline \multicolumn{3}{|l|}{ Motion of the ankle } \\
\hline $\begin{array}{l}\text { Within } 10^{\circ} \text { of uninjured } \\
\text { ankle }\end{array}$ & 16 & $72.7 \%$ \\
\hline $\begin{array}{l}\text { Within } 15^{\circ} \text { of uninjured } \\
\text { ankle }\end{array}$ & 4 & $18.2 \%$ \\
\hline $\begin{array}{l}\text { Within } 20^{\circ} \text { of uninjured } \\
\text { ankle }\end{array}$ & 2 & $9.1 \%$ \\
\hline
\end{tabular}

Regarding pain intensity, this study showed that the pain intensity among the studied group had average of 
$14.1 \pm 1.4$ that ranged from 12 to 15 . The range of stability among the studied group had average $14.7 \pm 0.2$ ranged from 13 to 15 . The range of walk had average of $14.5 \pm 1.6$ that ranged from 8 to 15 . The range of run had average of $8.1 \pm 1.2$ that ranged from 6 to 10 . The range of work had average of $9.5 \pm 1.1$ that ranged from 6 to 10. The range of motion ankle had average of $9.1 \pm 1.7$ that ranged from 4 to 10 . Finally, the range of X-ray had average of $24.4 \pm 0.4$ that ranged from 24 to 25 . Baird and Jackson's scoring system was $95.3 \pm 4.9$ that ranged from 76 to 98 . Most of the studied group, $68.2 \%$ had excellent outcome, $22.7 \%$ of them had good outcome and $9.0 \%$ had poor outcome (Table 4).

Table (4): Baird and Jackson's Scoring System among the studied group

\begin{tabular}{||l|l|c|}
\hline Variable & Variables & $\begin{array}{c}\text { The studied group(22) } \\
\text { Mean } \pm \text { SD }\end{array}$ \\
\hline \hline \multirow{4}{*}{ Baird and } & $\begin{array}{l}\text { Pain } \\
\text { intensity }\end{array}$ & $14.1 \pm 1.4$ \\
\cline { 2 - 3 } Jackson's & Stability & $14.7 \pm 0.2$ \\
\cline { 2 - 3 } $\begin{array}{c}\text { Scoring } \\
\text { System }\end{array}$ & Walk & $14.5 \pm 1.6$ \\
\cline { 2 - 3 } & Run & $8.1 \pm 1.2$ \\
\cline { 2 - 3 } & Work & $9.5 \pm 1.1$ \\
\cline { 2 - 3 } & $\begin{array}{l}\text { Motion } \\
\text { ankle }\end{array}$ & $9.1 \pm 1.7$ \\
\cline { 2 - 3 } & X-ray & $24.4 \pm 0.4$ \\
\hline
\end{tabular}

Table (5) showed that most of the studied group $(90.9 \%)$ did not have any complications and only two patients $(9.1 \%)$ had superficial infection, which was controlled by antibiotic and dressing.

Table (5): Complications distribution among the studied group

\begin{tabular}{|l|c|c|}
\hline Complications & NO (22) & \% \\
\hline \hline No & 20 & $90.9 \%$ \\
\hline $\begin{array}{l}\text { Superficial } \\
\text { infection }\end{array}$ & 2 & $9.1 \%$ \\
\hline
\end{tabular}

\section{DISCUSSION}

Concerning of injury, $63.6 \%$ patients in our study with only medial malleolus injury and $36.4 \%$ had combined medial and lateral malleolus injury. Patients with combined both medial and lateral malleoli were managed using antiglide plate for medial malleolus \& semitubular plate for lateral malleolus, while patients with only medial malleolus injury was managed by antiglide plate. This is in agreement with Palmanovich et $\boldsymbol{a l} .{ }^{\left({ }^{(6)}\right.}$ who reported that the majority of the ankle fractures commonly occur in relation to lateral or medial malleolar fractures.

Concerning bony union after antiglade plate in our study, the union duration was $12.1 \pm 2.2$ weeks that ranged from 9 to 16 weeks. Most of the studied group
(59.1\%) had healing time ranged from 9 to 12 weeks. this is the same as Ahn et $_{\text {al. }}{ }^{(7)}$ in their study, which included 70 patients that were followed up for a minimum of 12 (mean 55, range 12 to 109) months. Bony union was obtained in all cases after a mean of 57 (range 37 to 81 ) days (nearly 14 weeks). Additionally Sukur et al. ${ }^{(8)}$ found in their study that the follow-up evaluation at the 12th postoperative week showed union in all patients where the presence of a bridging callus in at least 3 cortices or the disappearance of the fracture line was accepted as radiological union.

As regards the outcome after the follow up period, the total final Biard and Jackson score ${ }^{(9)}$ was $95.3 \pm$ 4.9 that ranged from 76 to 98 . Most of the studied group (68.2\%) had excellent outcome, $22.7 \%$ of them had good outcome and $9.0 \%$ had poor outcome. This is consistent with the outcome of most studies as Velez et $\boldsymbol{a l} .^{(10)}$ with $4.5 \%$ of cases with poor functional results. In addition, in the study of Singh $\boldsymbol{e t} \mathbf{a l} .{ }^{(\mathbf{1 1})}$, they reported $5.4 \%$ had poor results. Besides, the clinical outcome of plating fixation of displaced fractures is satisfying and poor results are infrequent ${ }^{(7)}$. Moreover, the total outcome of the current study is in agreement with Jones et al. ${ }^{(12)}$ who concluded that antiglide plating technique with lag-screw placement is biomechanically superior to the other 2 constructs commonly used. However, the outcome of the current study is close to Kilian et al. ${ }^{(13)}$ where the final total score was $94.5 \pm 6.0$ (range 85100) points but they showed no dissatisfied patients.

Regarding complications in our current study, most of the studied group (90.9\%) didn't have any complications and only two patients (9.1\%) had superficial infection with no other complications. This is in contrast with Kilian $\boldsymbol{e t}$ al. ${ }^{\left({ }^{(13)}\right.}$ where complications were observed in $3(15 \%)$ patients of an antiglide plate (2 hardware irritation \& 1 skin reaction with no infection).

\section{CONCLUSION}

Surgical management of vertical shear of medial malleolus fracture gave excellent anatomical reduction and rigid fixation to restore articular congruity, help to facilitate early mobilization and hence to achieve optimal ankle function. Osteosynthesis using the small T-plate in the vertical shear of medial malleolus fracture gave a good choice of rigid fixation. The antiglide plate fixation is readily available and cost significantly less than a precountoured anatomicspecific type of fixation.

\section{REFERENCES}

1. Wegner A, Wolinsky P, Robbins $M$ et al. (2016): Antiglide plating of vertical medial malleolus fractures provides stiffer initial fixation than bicortical or unicortical screw fixation. Clin Biomech., 31: 29-32 .

2. Heckman J, Bucholz R, Tornetta $P$ et al. (2015): Rockwood and green's fractures in adults. Philadelphia: Lippincott Williams \& Wilkins, Pp: 2400. 
https://www.ncbi.nlm.nih.gov/ nlmcatalog/101258565

3. Blake S, Yakubek G, Shaer J (2015):Use of a Locked Fibular Plate for Fixation of a Vertical Shear Medial Malleolus Fracture: A Case Report. J Foot Ankle Surg., 54 (6):1202-5.

4. Simanski C, Maegele M, Lefering $\mathrm{R}$ et al. (2006): Functional treatment and early weightbearing after an ankle fracture: a prospective study. J Orthop Trauma, 20: 108-114.

5. Dumigan R, Bronson D, Early J (2006): Analysis of fixation methods for vertical shear fractures of the medial malleolus. J Orthop Trauma, 20: 687-691 .

6. Palmanovich E, Ohana N, Yaacobi E et al. (2020): Preoperative planning and surgical technique for optimizing internal fixation of posterior malleolar fractures: CT versus standard radiographs. J Orthop Surg Res., 15: 1-9 .

7. Ahn J, Kim S, Lee J et al. (2016): Incidence of peroneal tendinopathy after application of a posterior antiglide plate for repair of supination external rotation lateral malleolar fractures. J. Foot Ankle Surg., 55: 90-93 .
8. Sukur E, Akmanb Y, Gokcenc H et al. (2017): Open reduction in pilon variant posterior malleolar fractures: radiological and clinical evaluation. Orthop Traumatol Surg Res., 103: 703-707 .

9. Baird R, Jackson S (1987): Fracture of the distal part of fibula with associated disruption of the deltoid ligament. J Bone Joint Surg., 69: 1346-52.

10. Velez N, Moreno A, Martínez O et al. (2004): Posterior antiglide plate vs lateral plate to treat Weber type B ankle fractures. Acta Ortopédica Mex., 18: 39-44 .

11. Singh R, Kamal T, Roulohamin $N$ et al. (2014): Ankle fractures: a literature review of current treatment methods. Open J. Orthop., 4: 292-303 .

12. Jones D, Cannada L, Bledsoe J (2016): Are hook plates advantageous compared to antiglide plates for vertical shear malleolar fractures. Am J Orthop., 45: 98-102.

13. Kilian M, Csörgö P, Vajczikova $S$ et al. (2017): Antiglide versus lateral plate fixation for Danis-Weber type B malleolar fractures caused by supination-external rotation injury. J Clin Orthop Trauma, 8: 327-331 . 